\title{
Indonesian and Korean high school student's disparities in science learning orientations: an approach to multi-group structural equation modeling
}

\author{
Arif Rachmatullah ${ }^{1}$ and Minsu Ha ${ }^{2^{*}}$ (D)
}

\author{
* Correspondence: msha@kangwon. \\ ac.kr \\ ${ }^{2}$ Division of Science Education, \\ Kangwon National University, \\ Chuncheon-si, Gangwon-do, \\ Republic of Korea \\ Full list of author information is \\ available at the end of the article
}

\begin{abstract}
The primary purpose of the current study is to identify the differences between Indonesian and Korean high school students with regard to science learning orientations based on the inter-correlation between conceptions of, approach to and self-efficacy in learning science. A total of 1241 Indonesian and Korean high school students (609 Indonesian and 632 Korean) participated in this study. There were three translated research instruments used in the study, namely; the conceptions of learning science (COLS), the approach to learning science (ALS) and the science selfefficacy, which were all used to identify students' learning orientations in both countries. A Rasch model analysis was performed to seek validation of the instruments, and to obtain students' scores in the interval data form. The Pearson correlation test and a multi-group structural equation modeling were run to respond to the primary purpose of the current study. Based on the results, the current study generated an acceptable model of inter-correlation between COLS, ALS and science self-efficacy. Further analysis using a multi-group analysis generated an acceptable model indicated. The model was significantly different, as mediated by country and notated significant differences in the several identified paths. Cultural impacts on the learning orientations are discussed in order to understand the differences noted in this case.
\end{abstract}

Keywords: Cross-cultural study, Learning orientations, Multi-group analysis, Science learning, Secondary students

\section{Introduction}

Science education researchers have been scrutinizing many students' affective aspects when learning science, in order to fully understand students' psychological background that might help them to learn science in a more meaningful way. Those affective aspects include science motivation, metacognitive skills, science epistemological beliefs, engagement in the science classroom, conceptions of learning, learning strategies, and even their confidence in learning science. Among those variables, several recent studies in science education have focused on scrutinizing the way students are conceiving of their science learning. Given these points, it was found that there are several influences present as the base for the students to use as they decide to choose their learning

(c) The Author(s). 2019 Open Access This article is distributed under the terms of the Creative Commons Attribution 4.0 International License (http://creativecommons.org/licenses/by/4.0/), which permits unrestricted use, distribution, and reproduction in any medium, provided you give appropriate credit to the original author(s) and the source, provide a link to the Creative Commons license, and indicate if changes were made. 
strategies (e.g. Lee et al. 2008; Tsai 2004). Tavakol and Dennick (2010) and Zheng et al. (2018) found that kinds of learning strategies taken by students are significantly correlated to their self-efficacy, which is known as the one of the significant aspects in predicting the student's learning. Additionally, Shen et al. (2016) study suggested that taken together and reviewing these three student's affective aspects; conceptions of (COLS), approaches to (ALS) and self-efficacy in learning science, these factors can be used in determining student's learning styles or orientations in the learning of science subjects.

Entwistle and Ramsden (1983) have proposed the categorizations of a student's learning orientations that are based on the complexity of the correlation between the three variables mentioned above. They proposed four categories of a student's learning orientation namely meaning, reproducing, achieving, and apathetic orientations. In relation to the categorizations, student's socio-cultural backgrounds are found as the variance impacting the types of learning orientation that students had (Entwistle and Ramsden 1983), and the country effect as well as the influences of culture featured with the country, were found as the most influential factor in determining student's learning orientations (Marambe et al. 2012; Neuman and Bekerman 2001). To date, there is a limited finding in the body of the relevant science education research known to be focusing on the student's learning orientations based on COLS, ALS and self-efficacy in the learning of science. This may contribute to explain the differences of the student's learning outcomes (Rachmatullah et al. 2017; Chin and Brown 2000; Zeldin et al. 2008) that for more than a decade are routinely assessed by international programs such as the Programme for International Student Assessment (PISA) and the Trends in International Mathematics and Science Study (TIMSS). Therefore, the current study attempts to seek the effect of country in mediating the correlations between the three variables, through generating a model based on structural equation modeling (SEM) technique, to the samples from two representative countries based on achievement in PISA and TIMSS, Indonesia and Korea. Indonesia and Korea were chosen as the samples for this study because of the consideration from PISA and TIMSS results (Mullis et al. 2016; OECD 2016). Based on their results, Indonesia has been considered as a low achiever country in scientific literacy and always ranked in the bottom tenth for this aspect. In contrast, Korea is one of the higher achieving countries where students always rank in top ten. Not only did PISA and TIMSS assess scientific literacy, they also analyzed students' science learning confidence and motivation from which they obtained very interesting findings. Indonesian students had a very high confidence and motivation to learn science, while Korean students were found to have low confidence and motivation to learn science. These intriguing results were the main reasons we conducted this study. We wanted to gain more insights into how these two learning domains (cognitive and affective domains) which were hyposthesized to be positively correlated one another but such correlation was not evident. Additionally, based on our previous study on reviewing the cultural, economics and education system in both countries, we found that Indonesia and Korea have a very distinct characteristics which we believe may influence on such phenomenon as well as the learning orientations students have in both countries (Rachmatullah et al. 2019 for more detail).

The current study attempts to find the differences in both countries student's learning orientations based on the paths from the generated model through performing multi-group analysis. By way of the Shin et al. (2018) and Velayutham et al. (2012) 
studies, it is recommended by a multi-group analysis as the methods to gain depth insights in the differences of two comparable groups based on the generated model. However, we are also aware of the findings that may not entirely be used in explaining the country effect on student's learning orientation in low and high achiever countries in scientific literacy, and we believe that this could be considered as a reasonable starting point to finding out the differences of achievement in such international assessment programs.

Prior to the findings and discussions about the differences in learning orientations of the students from two countries, the following section describes the previous studies on the relationship between the COLS, ALS, and self-efficacy in learning science. These reviews were also used as the base in establishing a hypothetical model. Moreover, brief reviews regarding cultural differences in the student's learning orientation from previous studies are also described.

\section{Literature review}

\section{Conceptions of (COLS), approaches to (ALS) and self-efficacy in science learning}

Tsai (2004) defines the conceptions of learning science as the way students note conceiving their previous experience for science learning in the form of beliefs and knowledge about the subject. Several studies have indicated that the way students conceive learning is that a hierarchically is clearly distinguishable in this process, which is leading to different strategies that the students take in the process of learning science (Lee et al. 2008; Marton et al. 1993; Säljö 1979; Tsai 2004). Tsai (2004) argued based on his phenomenological study on Taiwanese students that the student's conceptions of learning science in a broader scope may have consisted of two different types of conceptions; namely the reproductive and the constructivist conception. Generally speaking, the students with reproductive conceptions means that they think that learning science is essential as only an acquiring of knowledge to be used for obtaining a better score in a test. In contrast, students with constructivist conceptions perceive learning science as understanding more science concepts in order to obtain more valuable meaning of life. This theory by Tsai (2004) and later revised by the Lee et al. (2008) study, found that three specific conceptions of learning science are categorized as the part of the reproductive conceptions. Those three conceptions are learning science as (1) memorizing science facts, concepts, formulas and laws, (2) learning science as relevant for success in cognitive-related science tests, and (3) learning science as related to practicing and manipulating numbers and formulas to solve problems. In addition, the constructivist conception also is consisting of three conceptions, namely learning science as increasing one's own knowledge, learning science as applying a particular science-related knowledge to unknown problems, and learning science as understanding scientific phenomena in a more profound way in order to obtain a new perspective about natural phenomena.

Many studies have obtained pieces of evidence both in qualitative and quantitative studies, noting that students with reproductive conceptions of learning science tend to use lower level of learning strategy and motive, called the surface approach, while students with constructivist conceptions are prone to use higher hierarchy of learning strategy and motive such as called a deep approach (Lee et al. 2008; Shen et al. 2016; Tsai 2004; Zheng et al. 2018). However, Koballa Jr et al. (2000) and Tavakol and Dennick (2010) later 
supported with findings from Shen et al. (2016) and Zheng et al. (2018) found that students who have lower conceptions of learning also could use higher level of learning approaches, and vice versa for the higher conceptions. In a further sense, Koballa Jr et al. (2000) and Tavakol and Dennick (2010) indicated this phenomenon that students use mixed-approaches to process their learning, especially in the area of learning sciencerelated subjects.

Regarding self-efficacy, Bandura (1977) based on his social cognitive theory, explained self-efficacy as the students' beliefs in on their abilities to successfully process their learning task and achieve desirable learning outcomes. Several studies have found that self-efficacy is highly correlated to and explained by the variance of the student's achievements, especially in science (Bandura 1977; Robnett et al. 2015; Zheng et al. 2018). Thus, the student's self-efficacy is considered as an essential part of the student's learning process. However, Bandura (1977), Chin and Brown (2000) and Zeldin et al. (2008) stated that the student's self-efficacy is exerted from their previous learning experiences that stimulate student's learning management and regulation skills. In another sense, the different type of conceptions and approaches that the students have corresponds to the level of their self-efficacy. Higher conceptions of and approaches to learning science correspond to the higher self-efficacy that students had, and vice versa for the lower hierarchies (e.g. Rachmatullah et al. 2018a; Zheng et al. 2018). Many studies have found that approaches to learning mediate the correlation between conceptions and self-efficacy. However, the Shen et al. (2016) and Tsai et al. (2011) studies focused on using the SEM technique to examine the Taiwanese and Chinese students and their learning approaches, and found that the conceptions of learning as applying which is part of constructivist conception had a direct effect to the student's selfefficacy. This prompted the current study to also examine this direct effect of constructivist conception to science self-efficacy, to the model generated from Indonesian and Korean students. Given that Rachmatullah et al. (2018a), Marambe et al. (2012) and Neuman and Bekerman (2001) stated that the magnitude of correlations between COLS, ALS and self-efficacy in learning science is influenced by country, it is an idea worth examining at this time.

\section{Learning orientations and country effects on it}

Many studies on this topic have defined the meaning of learning orientation, but most of the explanations suggested in the literature are quite different in some ways and similar in other ways. Some studies also use the term of orientation of studying (e.g. Entwistle and McCune 2004) or even learning style (Biggs 1979; Richardson 2011) interchangeably with learning orientation. Broadly speaking, learning orientation as addressed in this paper corresponds to what theories were suggested by Entwistle and Ramsden (1983) as the student's collective affective aspects, mainly including their motives, intentions, and processes of studying and learning. Entwistle and Ramsden (1983) suggested four different types of orientation that students have; namely reproducing, meaning, achieving and nonacademic orientation. Likewise, the reproducing orientation refers to the indication of the use of a surface approach to process learning and strongly relies on the syllabus. The orientation is also mainly associated and driven by the fear of failure, anxiety and extrinsic motivation. In contrast, the meaning orientation indicated the use of a deep approach to process learning, 
as the result of high intention to gain more understanding through learning. Students who are meaning oriented are mostly eager to be engaged in comprehension learning, systematic thinking, and explain with the use of evidence. All of these traits are internally motivated in the student. The third orientation is the student achieving orientation. Students who are achieving oriented tend to be aware of syllabus, but they process learning through every possible effort, including the use of mixed approaches - surface and deep, leading to what so-called as disorganized studying. Students with this orientation only pursue achievement in their studies. Lastly, the nonacademic orientation indicated a negative attitude towards learning, such as indicated by a low level of self-efficacy; also students with this orientation tend to have what Pask (1976) called as learning pathologies, characterized with "improvidence and globetrotting."

An abundant amount of works of literature in student's learning orientation has suggested that the student's learning orientation is depended on the culture that influences the students (Manikutty et al. 2007; Marambe et al. 2012; Neuman and Bekerman 2001). Students from one culture may have a different learning orientation in comparison to other students from other cultures. As culture is known to be heavily weighing in the life system of a particular society, culture does not only cover the traditional caring method of parents, socioeconomic status of country, as well as educational system and curriculum, are also considered as the derivatives of culture, at least indirectly. With the complexity of culture, it may be considered obvious that the students from one country to other countries have different type of learning orientations. Many studies on the student's learning orientation have been carried in the subject of language and mathematics (e.g. Jones et al. 2003; Manikutty et al. 2007; Oxford and Anderson 1995; Park 1997; Philbin et al. 1995), while it is limited to find a relevant study in the science subject. However, many intriguing findings obtained from those studies have shown differences in the student's learning orientation based on the student's culture. Findings from Asians with Confucian culture have indicated that these cultures are prone to be reproducing oriented (e.g. Marton et al. 1997; Park 1997; Wong 2004), leading to stereotyping them as 'the Asian as a rote learner,' but at the same time people are stereotyping the people from these cultures typically as 'the Brainy Asian,' indicating that these students tend to have meaningful learning orientation (Marton et al. 1997). In line with the Indonesian samples, there have also been examples of this idea used in several studies on learning orientations. Ajisuksmo and Vermunt (1999) study found that Indonesian university students used stepwise processing strategies, which are prone to memorizing and rehearsing, analyzing, and concrete processing. In the Marambe et al. (2012) comparison study and the Charlesworth (2008) study, the Indonesian students used memorizing as well as rehearsing strategies more often (reflector style), and had less use of relating, structuring, thereby noting that they had lowest on active learning style.

Aforementioned that the previous studies have mainly obtained results from the subject of language and mathematics, and most of the participants of these studies were university students. The current study attempts to find out more the effect of culture on the high school student's learning orientation in a science subject, by comparing Indonesian and Korean high school students. Prior to the analysis, this paper also provides a brief description of Indonesian and Korean differences in cultural and economic aspects, which contribute to establishing the hypothesis. 


\section{Indonesian and Korean culture and economic status related to education}

Indonesia is known as a developing country, which is now trying to improve the country economic status with maximizing the products from science, technology, engineering and mathematics (STEM) sectors (World Bank 2017). Based on the OECD (2017), Indonesia uses $1.2 \%$ GDP for education, which is considered less far from the OECD country's average $2.1 \%$. As the country's expenditure for education is used for providing a better school environment leading to better educational performances, this expenditure has not been enough to make the Indonesia science education program into a superior level, as shown by the Indonesian student's performance in international assessments, such as the PISA and the TIMSS. Based on those assessments, Indonesians students for more than a decade are always in the bottom rank (OECD 2016; Mullis et al. 2016).

Regarding the Indonesian culture, it is hypothesized that the performance of the teachers may directly impact the students' learning orientation. In Indonesia, the teacher is called a "guru," which is derived from Javanese words "digugu Ian ditiru," which means a person that must be listened to and who should be obeyed (Ajisuksmo and Vermunt 1999). The role of the teacher in Indonesia culture has the power and dominant instructional practice in the classroom environment, while the students are viewed as a person who needs to listen to whatever the teacher is telling them during the classroom instruction timeframes. Therefore, in the teaching and learning activities, students need to memorize information that is delivered by the teacher. Moreover, Ajisuksmo and Vermunt (1999) add incidentally, that the teacher's salary is too low, which might force some of them to find side jobs to make up a fuller income, and for this reason, the teachers do not have enough time to develop their knowledge and teaching skill. Consequently, they may use the traditional approach of process of transferring information to teach their students. Lewis (1997) also argues of the cultures impact which is found on the influence of the home (family) education, where students usually learn to memorize prayers, dogmas, songs, or principles of the state to accept their identity as Indonesian, as a person who religious (as Muslim or Christians), or to show off or perform for their parents.

In contrast, economically, Korea is categorized as a developed-industrial country with mature and abundant products from the identified STEM sectors (Watkins and Ehst 2008). Korea is also known as one of the countries that has a high expenditure on education, which is noted to be around 2.3\% of the GDP (OECD 2017). Globally speaking, this above-average expenditure for education has made Korea one of the high achieving countries and has produced successful science education practitioners globally speaking. Whereas the science achievements of the successful Korea's successful students that may prompt some world citizens to refer to Koreans (along together with Chinese and Japanese) as "Brainy Asians," more often, world citizens seem more apt to refer to Asians as "rote learners." Korea together with mainland China, Taiwan, and Japan have all shared a common Confucian culture. In the Confucian culture, a chil's failure in school is considered as the family's failure as well; thus the family tends to give more pressure to students to succeed (Stankov 2010). This can leadstudents to generally have more anxiety and self-doubt. The self-doubt, pressure and anxiety placed on students from their families, may prompt the students to only focus on increasing their attainment of high grades in school, and may encourage them to keep studying through the use of memorizing techniques (e.g. Li and Cutting 2011; Suen and Yu 2006; Watkins and Biggs 1996). 
However, many have different opinions regarding the impact of Confucian culture on studying. For instance, Ji (2010) argues that the reason why many students from the Confucian culture tend to have more anxiety, self-doubt and use memorizing is because many schools in Confucian countries emphasize the importance of the school and or national ranking system, which is so transparent, that it is open and usually shows the student's grading marks in public. Thus, it may lead to an increase in the students' anxiety about receiving failing grades in schools. Based on this, in some sense there may be similarities or even differences between the Indonesian and Korean students' learning orientations, but to date there is no study statistically examining these similarities and differences based on the inter-correlation between the three major psychological aspects of students' science learning; COLS, ALS and the influences and impacts of the student self-efficacy in learning science.

\section{Hypotheses and research questions}

Based on the description above, a hypothetical model of the inter-correlation between the COLS, ALS, and self-efficacy in learning science was established to be examined using the Indonesian and Korean samples. The hypothetical model featured with every path hypothesis is visualized in Fig. 1. The hypotheses are as follows:

H1. There is a significant direct positive effect of constructivist conceptions on the deep approach.

$\mathrm{H} 2$. There is a significant direct negative effect of constructivist conceptions on the surface approach.

H3. There is a significant direct negative effect of reproductive conceptions on the deep approach.

H4. There is a significant direct positive effect of reproductive conceptions on the surface approach.

H5. There is a significant positive direct effect of constructivist conceptions on the self-efficacy.

H6. Deep approach has a positive significant direct effect on the self-efficacy.

H7. Surface approach has a negative significant direct effect on the self-efficacy.

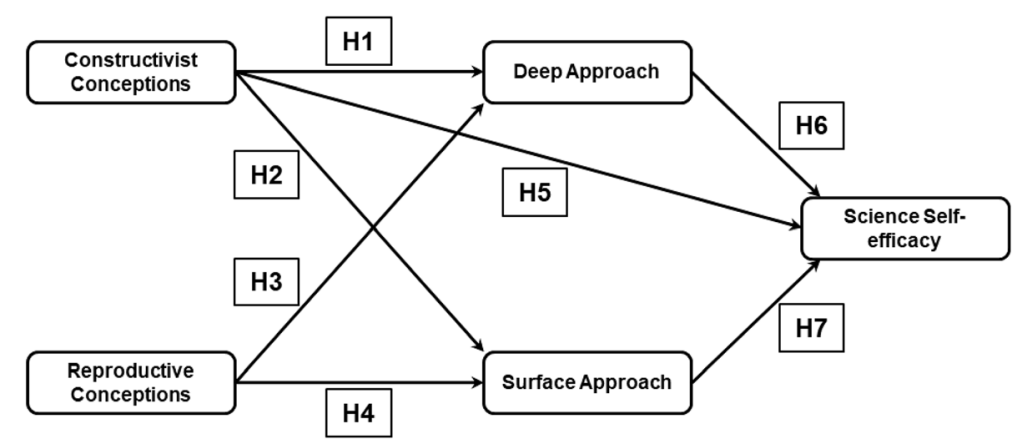

Fig. 1 The hypothetical model 
Following the examination of the hypothetical model, we proposed two research questions in order to create more a focus discussion of the current study. Those two research questions are as follows:

1. Is the hypothetical model based on previous studies acceptable for the samples of the Indonesian and Korean high school students?

2. To what extent does the country mediate the correlations between the COLS, ALS, and the self-efficacy in learning science tested in the generated model?

\section{Methods}

\section{Participants}

The data of the current study were gathered from eight Indonesian general and Islamic-based high schools and six Korean general high schools. A total of 1241 high school students, which was noted to consist of 609 Indonesian and 632 Korean students, participated in the current study. Most of them were in their first and second grade, and some were in the third grade of high school level. In terms of gender, the Indonesian data were composed of $37 \%$ males and $63 \%$ females, while the Korean data were quite equally distributed by gender with $51 \%$ males and $49 \%$ females.

\section{Research instruments}

Three instruments were used in the current study. The two instruments, which are instruments measuring conceptions of learning science (COLS) and approaches to learning science (ALS) were developed by the Lee et al. (2008) study, while the instrument measuring science self-efficacy was developed by the Glynn et al. (2011) study. All of the used instruments were carefully translated by English-Indonesian and English-Korean experts and were also checked by three experts in science education for readability issue. The validity and reliability of the instruments were examined through performing Rasch model analyses and a traditional Cronbach's alpha. The cut-off of infit and outfit mean-square (MNSQ) was based on the Boone et al. (2014) study, which is ranged from $0.50 \sim 1.50$, and was used to validate the instrument.

The COLS instrument had initially consisted of 31 items with six constructs, and three constructs (increasing one's knowledge five items, applying four items and understanding and seeing in a new way six items), with a total of 15 items measuring the constructivist conceptions $(\mathrm{CT})$ and three constructs (memorizing five items, testing six items and calculating and practicing five items), with a total 16 items measuring reproductive conceptions (RP). However, the current study did not use all of the items in the final analysis, because we found three items (testing_2 and testing_3) of reproductive conception construct were considered a highly factored misfit with the MNSQ value by more than 1.80 . Thus, only total 13 items were included in the final analysis for measuring the reproductive conception. Among those total 14 items, one item was found outside the cut-off range, but the value was not that far from the range (1.60 and 1.63 for infit and outfit respectively). We retained this item because if we remove this item from analysis the number of items residing the Testing subscale would be very small compared to the other subscales in the reproductive conception. Although, it may impact the students estimated logit score, but we believe the impact would not be 
significant. However, we also acknowledge this as one limitation of this study. The psychometrical properties of the used COLS instrument are presented in Table 1. In terms of the Indonesian COLS data used in the current study, were to include the data as used in our previous study (Rachmatullah et al. 2017).

The ALS instrument used in the current study has a similar total item with the original version, which is 24 items. Those items are divided into four constructs; surface motive (five items), deep motive (eight items), surface strategy (five items), and deep strategy (six items). Generally speaking, the surface motive and strategy were used to measure the surface approach (SA), and the deep motive and strategy were used in measuring the deep approach (DA). The psychometrical properties of the used ALS instrument are presented in Table 1.

The Self-efficacy instrument used in the current study was one part of the constructs of the Science Motivation Questionnaire II (SMQ-II), as developed by the Glynn et al. (2011) study. It has five items, and all of the items were used in the current research. The psychometrical properties of the used ALS instrument are presented in Table 1.

\section{Data analyses}

The obtained data gathered from the participants were in the categorical form data; thus, the conversion to the interval form data was taken through performing a Rasch analysis with rating scale model. This conversion was done in order to make the data meet the requirements for further statistical analysis, particularly a parametric one. After conversion, the students' score may be interpreted based on the negative and positive signs the scores have. Based on Boone et al. (2014), students who have logit scores lower than zero, or negative scores, they have negative agreement towards the construct. This interpretation is vice versa for the positive scores. Once the data had been converted, a Pearson correlation test was run to find out whether the used variables were significantly correlated or not. Following this analysis, a hypothetical model was examined through the SEM technique. The cutoff of fit indices suggested by Hu and Bentler (1999), Yu (2002) and Schumacker and Lomax (2004) was used to evaluate the model. They suggested that the good model has a standardized root mean square residual (SRMR) below .08, with a normed fit index (NFI) and an adjusted goodness of fit index (AGFI) of more than .90, a comparative fit index (CFI) and a Tucker-Lewis index (TLI) above .95 and a root-mean-square error of approximation (RMSEA) less than .08. Then, a multi-group analysis featured with a chi-square test (CMIN) was performed to evaluate the country effect on the obtained acceptable model. The model is significantly different when the $p$-value computed from chi-square is less than .05. Lastly, $z$-square tests were performed to find out the differences between the two countries in every

Table 1 The psychometrical properties of the used instruments

\begin{tabular}{lllllllll}
\hline $\begin{array}{l}\text { Variable } \\
\text { of items }\end{array}$ & $\begin{array}{l}\text { Number } \\
\text { of item deleted }\end{array}$ & $\begin{array}{l}\text { Range of } \\
\text { if item measure }\end{array}$ & Infit MNSQ & Outfit MNSQ & $\begin{array}{l}\text { Person } \\
\text { reliability }\end{array}$ \\
\hline CT & 15 & .934 & $.928 \sim .932$ & $-0.72 \sim 0.59$ & $0.80 \sim 1.45$ & $0.79 \sim 1.50$ & .90 & .98 \\
RP & 14 & .875 & $.862 \sim .877$ & $-0.51 \sim 0.79$ & $0.77 \sim 1.60^{\mathrm{a}}$ & $0.79 \sim 1.63^{\mathrm{a}}$ & .85 & .99 \\
DA & 14 & .944 & $.939 \sim .942$ & $-1.00 \sim 0.77$ & $0.74 \sim 1.24$ & $0.75 \sim 1.32$ & .92 & .99 \\
SA & 10 & .757 & $.716 \sim .756$ & $-0.83 \sim 1.04$ & $0.81 \sim 1.25$ & $0.83 \sim 1.24$ & .75 & 1.00 \\
SE & 5 & .919 & $.895 \sim .911$ & $-0.56 \sim 0.54$ & $0.83 \sim 1.28$ & $0.79 \sim 1.27$ & .88 & .98 \\
\hline
\end{tabular}

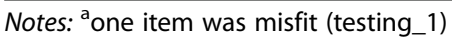


path in the model. It needs to be emphasized that the present study used means-based path analytic approach, not an entirely latent approach. Thus, what appears in the results will be the higher hierarchies of COLS and ALS, such as constructivist and reproductive conceptions and deep and surface approach. The lower level of the variables, such as memorizing, testing, etc. are not included in the analyses to form latent variables given the limited number of sample size. Therefore, the authors acknowledge this issue as one of limitations of the present study. All of the statistical analyses were performed through SPSS and AMOS version 22; however a Rasch analysis was completed through the use of a Winsteps 4.0.0.

\section{Findings}

\section{Descriptive statistics and correlations between COLS, ALS and science self-efficacy}

The means, standard deviations, and results of a Pearson correlation test are depicted in Table 2. It can be seen from Table 2, that the Indonesian students had a higher means than the Korean students in all variables, and this may be caused by a different effect of culture in the filling out of the questionnaires by the respondents. Moreover, it is quite difficult to interpret further the differences based on averages only. Therefore, a multi-group SEM was taken into account to further analyze the structure of the three variables. Prior to the analysis, the Pearson correlation test was performed as the preliminary analysis.

As seen in Table 2, all variables were found significantly correlated to one another $(p<.01)$. The two highest correlations were found between the deep approach and selfefficacy $(r=.70)$ and the constructivist conceptions and deep approach $(r=.55)$. The two lowest correlations were the correlation between the reproductive conceptions and self-efficacy $(r=.16)$ and the constructivist conceptions and surface approach $(r=.17)$.

\section{Multi-group structural equation modeling for COLS, ALS, and self-efficacy}

The tested hypothetical model featured with the standardized regression coefficients $(\beta)$ is visualized in Fig. 2. Based on the obtained fit of this model presented in Table 3, the model met the minimum cut-off of all indices suggested by the $\mathrm{Hu}$ and Bentler (1999), Yu (2002) and Schumacker and Lomax (2004) studies. Thus, the model can be indicated as a good and acceptable model. However, three out of seven hypotheses were rejected $(p>.05)$ based on this model using full sample of the Indonesian and Korean high school students. Those rejected hypotheses were the path from constructivist conceptions to surface approach (H2), the reproductive conceptions to deep approach (H3) and from the surface approach to self-efficacy $(\mathrm{H} 7)$.

Table 2 Descriptive statistics and Pearson correlation test's results for the used variables

\begin{tabular}{|c|c|c|c|c|c|c|c|}
\hline \multirow[t]{2}{*}{ Variable } & & \multicolumn{2}{|c|}{ Mean \pm SD (logit) } & \multirow[t]{2}{*}{$\mathrm{CT}$} & \multirow[t]{2}{*}{$\mathrm{RP}$} & \multirow[t]{2}{*}{$\mathrm{DA}$} & \multirow[t]{2}{*}{ SA } \\
\hline & & Indonesia & Korea & & & & \\
\hline Constructivist & $\mathrm{CT}$ & $2.42 \pm 1.58$ & $1.73 \pm 2.25$ & 1 & & & \\
\hline Reproductive & $\mathrm{RP}$ & $1.04 \pm 0.94$ & $0.40 \pm 1.30$ & $.316^{* *}$ & 1 & & \\
\hline Deep Approach & $\mathrm{DA}$ & $1.20 \pm 1.43$ & $-0.02 \pm 2.20$ & $.550^{* *}$ & $.196^{* *}$ & 1 & \\
\hline Surface Approach & SA & $0.51 \pm 0.66$ & $0.17 \pm 1.10$ & $.167^{* *}$ & $.408^{* *}$ & $.291^{* *}$ & 1 \\
\hline Self-efficacy & SE & $3.04 \pm 2.61$ & $0.54 \pm 3.65$ & $.449 * *$ & $.162^{* *}$ & $.703^{* *}$ & $.173^{* *}$ \\
\hline
\end{tabular}

** $p$-value $<.01$; no mark $p>.05$ 


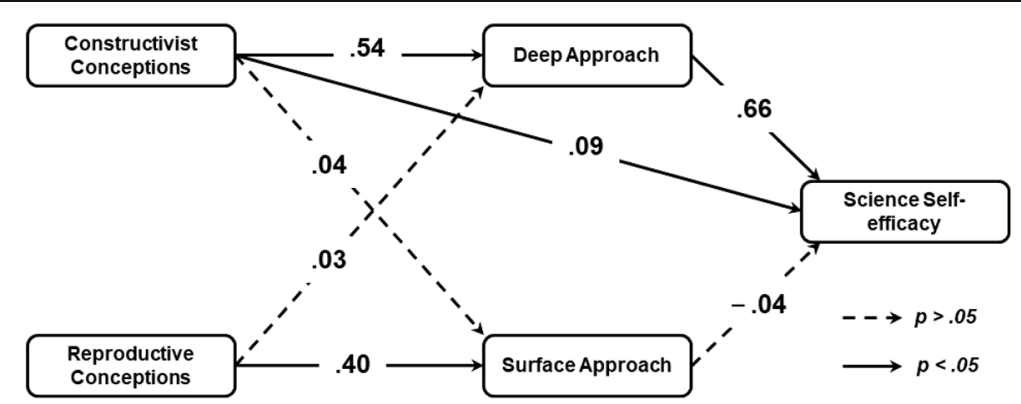

Fig. 2 Pathway analysis results of the hypothetical model featured with the standardized regression coefficients $(\beta)$ with full sample

Further analysis in finding out the effect of the country on the obtained accepted model was completed through the performing of a multi-group analysis. Based on the multi-group analysis indices presented in Table 3, the model was found to be wellfitted for the unconstrained model compared to weight constrained, and the model was found significantly different in both countries. Thus, further analysis using z-score test to compare every $\beta$ value of the paths in both countries was completed, and the results are presented in Table 4 and visualized in Fig. 3.

Based on Table 4, it can be seen that four paths were found to be significantly different in both country's models. First, it is noted that the Korean students $(\beta=.40)$ had significantly higher $\beta$ values than the Indonesian students $(\beta=.27)$ in the path from the reproductive conceptions to surface approach, also as noted in the path from the deep approach to self-efficacy ( $\beta=.73$ and $\beta=.35$, respectively). However, the Indonesian students $(\beta=.11)$ had significantly higher $\beta$ values than the Korean students $(\beta=-.10)$, in the path from the reproductive conceptions to deep approach and from the constructivist conceptions to self-efficacy $(\beta=.22$ and $\beta=.08$, respectively). Interestingly, different findings were found based on the multi-group analysis, as compared to the model with the full sample as visualized in Fig. 2. In the full sample, it was found that the reproductive conceptions had no significant effect on the deep approach $(\beta=.03$, $p>.05)$, however in the multi-group analysis result the effect did exist in both samples but in the different direction, such as noted as negative for the Korean sample $(\beta=-.10, p<.05)$, and identified as positive for the Indonesian sample $(\beta=.11$, $p<.05)$. Additionally, in the full sample model and only the Korean sample model were found no significant effect of the surface approach to self-efficacy $(\beta=-.04$, $p>.05)$, but in the Indonesian sample model, the effect did significantly exist with a noted negative direction $(\beta=-.10, p<.05)$.

Table 3 Fit indexes of the model and the multi-group analysis

\begin{tabular}{llllllll}
\hline & $\mathrm{X}^{2} / \mathrm{df}$ & SRMR & AGFI & NFI & TLI & CFI & RMSEA (CI90) \\
\hline Path model with full sample & 0.96 & .004 & .995 & .999 & 1.00 & 1.00 & $.000(.000 \sim .074)$ \\
Multi-group analysis & & & & & & & \\
$\quad$ Unconstraint & 2.63 & .015 & .975 & .997 & .980 & .998 & $.036(.000 \sim .076)$ \\
$\quad$ Weight constraint & 10.04 & .050 & .907 & .946 & .891 & .951 & $.085(.070 \sim .102)$ \\
Model comparison & $12.16(p<.01)$ & & & & & \\
\hline
\end{tabular}


Table 4 The comparison of every path's standardized $\beta$ values for both countries

\begin{tabular}{llll}
\hline Paths & \multicolumn{2}{l}{ Standardized $\beta$ values } & z-score \\
\cline { 2 - 3 } & Indonesia & Korea & \\
\hline Reproductive $\rightarrow$ Surface Approach & $.27^{* *}$ & $.40^{* *}$ & $3.41^{* *}$ \\
Constructivist $\rightarrow$ Deep Approach & $.61^{* *}$ & $.49^{* *}$ & -1.51 \\
Reproductive $\rightarrow$ Deep Approach & $.11^{* *}$ & $-.10^{* *}$ & $-4.24^{* *}$ \\
Constructivist $\rightarrow$ Surface Approach & .08 & .03 & -0.65 \\
Constructivist $\rightarrow$ Self-efficacy & $.22^{* *}$ & $.08^{*}$ & $-2.65^{* *}$ \\
Deep Approach $\rightarrow$ Self-efficacy & $.35^{* *}$ & $.73^{* *}$ & $5.63^{* *}$ \\
Surface Approach $\rightarrow$ Self-efficacy & $-.10^{* *}$ & -.04 & 1.55 \\
\hline
\end{tabular}

Notes: ${ }^{*} p$-value $<.01 ;{ }^{*} p$-value $<.05$; no mark $p>.05$

\section{Discussion and conclusion}

Many studies have reported that the COLS, ALS, and self-efficacy in learning science are correlated each other as supported with an acceptable statistical model (e.g., Shen et al. 2016; Tsai et al. 2011; Zheng et al. 2018). However, most of those studies used Taiwanese and/or Chinese students as the subjects of the reviewed study. As the Shin et al. (2018), Rachmatullah et al. (2018b) and Lee et al. (2008) study stated that students from different cultures may have different affective constructs in learning science, thus the current study attempted to confirm whether the acceptable statistical model of an inter-correlation between the COLS, ALS, and self-efficacy in learning science is also found to exist, by using samples from other countries, such as from Indonesia and

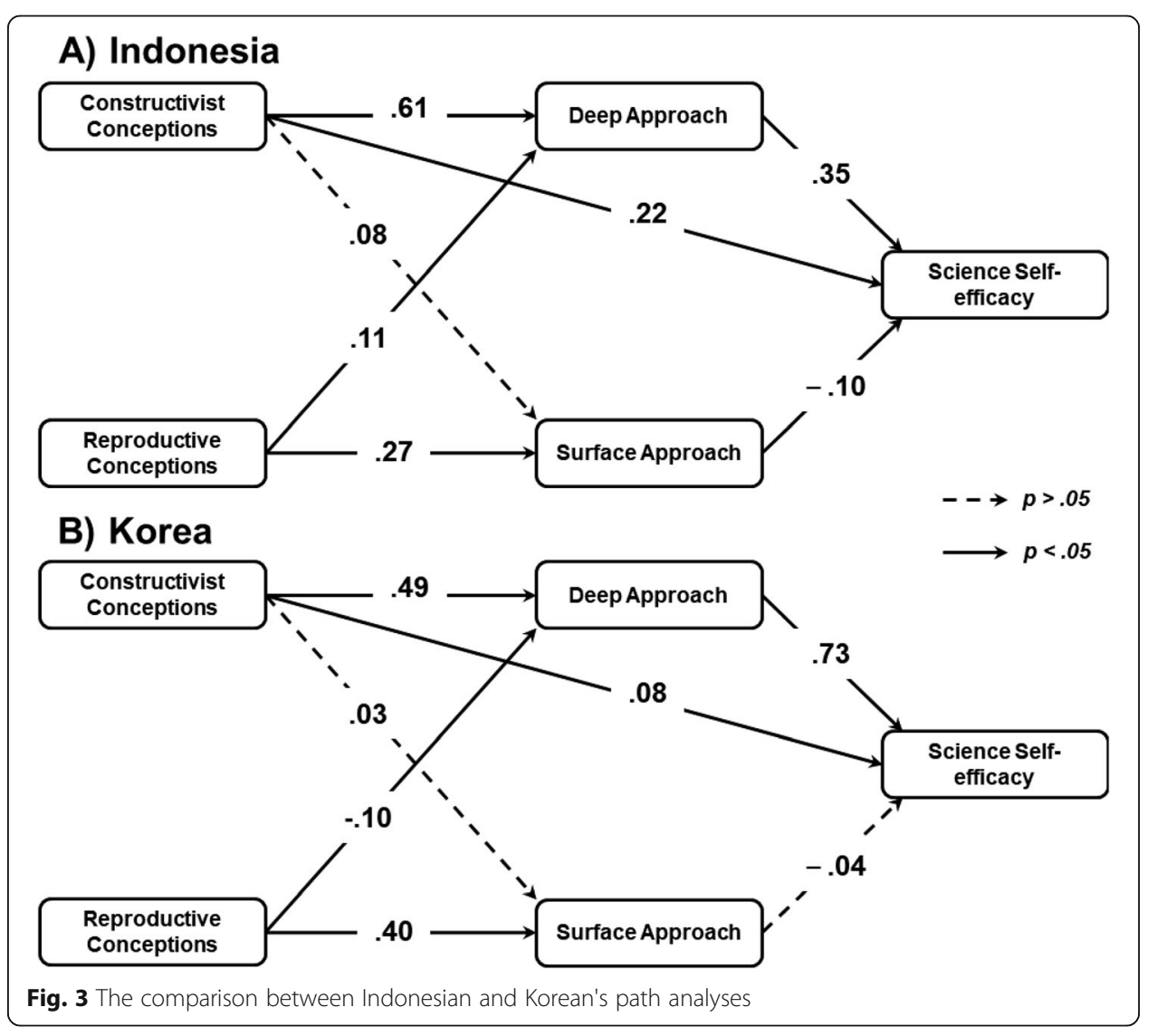


Korea. Based on the findings, the current study found that the three constructs were indeed correlated with each other, and conclusively supported with good and acceptable model indices. This suggests that the model of inter-correlation of the three investigated constructs is stable among Asian samples, both from a low and a high achiever scientific literacy achievement status.

By way of making sense of the results computed through a multi-group analysis, it may be determined that the Korean high school students tend to be more reproducing oriented when learning science as compared to the Indonesian students. This was shown by the results that the path weight (Table 4) from the reproductive conceptions to the surface approach was significantly higher in the model of the Korean students than in the Indonesian students. This result suggests that the Korean high school students are prone to conceive science learning as memorizing, testing and practicing and may influence the students such as to make them use more surface approach in learning science than with similarly situated and aged Indonesian students. Perhaps this is resulted from the societal factor of Korea, and from the Korean culture that is specific to Korea. As Anderson and Kohler (2013) stated that Korea now is facing a phenomenon called 'Education Fever,' meaning that in the broadest sense, the Korean people are eagerly working to pursue the best quality of education as they could for their children, and that the high school level is considered as the door for them to get the best education in the form of launching towards going to the best universities that are socially recognized, as located anywhere in the world. Many Korean parents put much effort to assist the efforts for their children to be accepted, enrolled, and eventually graduated from those kinds of universities. One of the efforts used by parents is to register their children in several non-formal academic institutions, in order that their children can study more during after school hours and have a higher opportunity to obtain better scores on the required standardized testing given to all students. Thus, it may stimulate Korean high school students to learn science in a more simple way such as memorizing and practicing, in order that they could be more familiar with the problems that may be offered later in a test, to increase their knowledge base and allow the students to easily obtain a better score. Moreover, as Ji (2010) stated that in many schools in East Asian countries, including Korea, the common practice of showing the student's scores and ranks to the interested public, at least in their internal environment, is stressful and this may contribute to the increase of a student's anxiety that will be an influence on learning. This type of pressure may offer students more incentive to concentrate on their studies and make them more focused on obtaining a higher rank in school, rather than obtaining more meaningful learning in the general sense of obtaining an education. As Entwistle and Ramsden (1983) stated that having more anxiety and relying much more on the syllabus are the main traits of the identified reproducing oriented students.

In terms of the Indonesian students, the model showed that the Indonesian high school students had positive paths from the constructivist and reproductive conceptions to deep approaches. This suggests that the Indonesian high school students are likely to have mixed conceptions of learning science and use deep approaches when processing science tasks. In other words, they conceive that learning science is both accumulating knowledge and giving them more value in their life. This mixed conception may be originated from their science learning experiences. Given that from 2013 
Indonesia has implemented a new science curriculum with an emphasis on the use of meaningful science teaching and learning in order to improve Indonesian student's achievements in international assessment programs; this is a meaningful assessment of the new learning focus initiated in Indonesia. However, science teaching and learning activities in Indonesian schools before 2013 were still implementing the traditional methods, as explained in the literature review part regarding the meaning of "Guru." Through a transition from the older curriculum to the new curriculum 2013, teachers may not be able to adapt as easily, whereby they may use the mixed teaching methods in an effort to manage the implementation to the new systems being launched in that country. Consequently, students conceived learning science in mixed ways. Based on Entwistle and Ramsden (1983), these traits may refer to achieving orientation, at least partially, meaning that the Indonesian high school students are prone to be aware of the science curriculum requirements, and they tend to process it in several approaches.

The findings (Table 4 and Fig. 3) of Korean and Indonesian students still partially endorsing traditional approach may be explained through what sociologist of Asian education called as "unconditional obedience to authority" (Liu 1998, p. 5). The phenomenon of students obeying what parents and teachers ask is considered as a typical issue in sociology of Asian education. Asian students are taught to obey what older people, including parents and teachers, are saying without intervening by students own thoughts. Therefore, it may result the on Asian students endorsing more reproductive conceptions and traditional approach for science learning compared to students in Western culture, as what Forestier (1998) found.

If Korean students are prone to be more academic-grade oriented, Indonesian students are prone to be more non-academics oriented. The Indonesian students perceive that having achievement in non-academic fields, such as extracurricular activities, is also considered as honorable endeavors in life. Based on Swadener and Soedjadi (1988), Indonesian parents, teachers, and society support every student's activities if the activities could give them some achievements in their life. Therefore, it may be the reason why Indonesian high school students tend to be more achieving oriented, as compared to being more academically oriented (as the Korean students appear to be according to our research in this study).

The findings of the current study are likely different to predictions based on the PISA or TIMSS results (Mullis et al. 2016; OECD 2016) in which Korea as a high achiever of scientific literacy and was predicted to have a better learning orientation than Indonesia. Perhaps the participant's level of education impacts this finding. As most of the students participating in the PISA are in the middle school level, and in case of the Koreans, they still do not have much pressure and anxiety, so that they can learn science in the 'fun' way, make them becoming more valuing science and learn it in meaningful way, leading to making them have higher scientific literacy score at the time of testing and scored ratings. However, in the high school level, pressure and anxiety are higher than in the middle school level, and for this reason they tend to be what has been explained above in regard to stressors and pressures noted by students at the high school level, who are focused and intent on securing a place at a formidable university. Thus, as what Watkins and Biggs (1996) stated, that the magnitude of pressure and anxiety that students have is significant to make them value the relevant teaching and learning activities, 
especially in science, it is significant that students will focus their attention for improving grades for this reason.

The findings from the current study also suggest that nurturing students to be engaged in using the noted deep approaches when they are learning science, is a method to assist positively influencing their science self-efficacy. This finding is in line with previous studies (Bandura 1977; Robnett et al. 2015; Zeldin et al. 2008; Zheng et al. 2018). However, a multi-group analysis showed that the magnitude effects of the students who did use the deep approach in learning science to their self-efficacy were found significantly different between Indonesian and Korean students as shown in Table 4. It can be seen from Table 4 that once the Korean high school students have engaged in the use of the deep approach in learning science; they are predicted to have higher science self-efficacy than the Indonesian students. As Zeldin et al. (2008) and Glynn et al. (2011) study stated, it is relevant that science self-efficacy positively influences internal motivation and scientific literacy. Thus, it is advisable for the Korean science teachers to consider nurturing their students to be engaged in using the deep approaches for better academic outcomes for the students. Additionally, it may be considered as an artifact of the otherwise low endorsement of the deep approach in learning science in which that only few Korean students endorsed a deep learning approach strongly, and those who did may be an atypical in the Korean context.

In terms of the result from the Indonesian samples, as they tend to be more achieving oriented and Entwistle and Ramsden (1983) indicated that the student with this orientation might have disorganized studying methods, and this also impacts their self-efficacy. As the current study found that even though Indonesian students tend to use the deep approach in science learning, but it does not profoundly impact their self-efficacy. It is advisable for the Indonesian science teachers to decrease the use of traditional teaching methods, and move forward to use entirely meaningful teaching methods. Therefore, the more impact on their science self-efficacy exerting from the deep approach would be achieved. Additionally, this may be the impact of overconfidence bias, as shown in the recent study conducted by Rachmatullah and Ha (2019). Further analysis and study are needed to understand more about this assumption.

Acknowledgements

We wish to express our gratitude to the students who participated in this study as well as the colleagues who supported it. We also thank Dr. Sariwulan Diana from Indonesia University of Education for her continued assistance and encouragement throughout this research. Finally, we would like to thank the anonymous reviewers for their helpful suggestions and feedback.

Authors' contributions

The first author, AR, conducted the research project and drafted the manuscript. The second author, $\mathrm{MH}$, made contributions to the conception and design of the study. Both authors read and approved the final manuscript.

\footnotetext{
Authors' information

Arif Rachmatullah is a Ph.D. student in the Department of STEM Education at North Carolina State University. His concentration is in Science Education. He received his Master of Education in Science Education from Kangwon National University-Korea and Bachelor's degree in Biology Education from Indonesia University of Education (UPI). He is particularly interested in science assessment and research instrument development and validation, confidence in science learning, cognitive biases, computational thinking and modeling, and cultural aspects of science learning. Upon being a doctoral student, he has been working on the projects around the development and implementation of computational scientific modeling curriculum.
}

Minsu Ha Ph.D. is an Associate Professor of Science Education at Kangwon National University (KNU), Republic of Korea. His research interests include biology education, science motivation, assessment and learning process in science education. 
Funding

Not applicable

\section{Availability of data and materials}

The datasets generated and/or analyzed during the current study are not publicly available due to ethical considerations. The data is not available for sharing due to the confidentiality clause included in the informed consent for the study.

\section{Ethics approval and consent to participate}

The data collected from this project has obtained the necessary clearance from the schools, guardians and the students involved in the study.

\section{Consent for publication}

The authors agree that this article will be published in the APSE journal.

\section{Competing interests}

The authors declare that they have no competing interests.

\section{Author details}

${ }^{1}$ Department of STEM Education, North Carolina State University, Raleigh, NC, USA. ${ }^{2}$ Division of Science Education, Kangwon National University, Chuncheon-si, Gangwon-do, Republic of Korea.

Received: 31 May 2019 Accepted: 13 November 2019

Published online: 18 December 2019

\section{References}

Ajisuksmo, C. R., \& Vermunt, J. D. (1999). Learning styles and self-regulation of learning at university: an Indonesian study. Asia Pacific Journal of Education, 19(2), 45-59.

Anderson, T., \& Kohler, H. P. (2013). Education fever and the east Asian fertility puzzle: a case study of low fertility in South Korea. Asian Population Studies, 9(2), 196-215.

Bandura, A. (1977). Self-efficacy: toward a unifying theory of behavioral change. Psychological Review, 84(2), 191-215.

Biggs, J. (1979). Individual differences in study processes and the quality of learning outcomes. Higher Education, 8(4), 381-394.

Boone, J., Staver, J. R., \& Yale, M. S. (2014). Rasch analysis in the human sciences. New York: Springer Science \& Business Media. Charlesworth, Z. M. (2008). Learning style across culture: Suggestion for educators. Education \& Training, 50(2), 127-155.

Chin, C., \& Brown, D. E. (2000). Learning in science: a comparison of deep and surface approaches. Journal of Research in Science Teaching, 37(2), 109-138.

Entwistle, N., \& McCune, V. (2004). The conceptual bases of study strategy inventories. Educational Psychology Review, 16(4), 325-345.

Entwistle, N. J., \& Ramsden, P. (1983). Understanding student learning. London: Croom Helm.

Forestier, K. (1998). Asian crisis spurs lesson in learning. South China Morning Post August, 11, 15.

Glynn, S. M., Brickman, P., Armstrong, N., \& Taasoobshirazi, G. (2011). Science motivation questionnaire II: validation with science majors and nonscience majors. Journal of Research in Science Teaching, 48(10), 1159-1176.

Hu, L. T., \& Bentler, P. M. (1999). Cutoff criteria for fit indexes in covariance structure analysis: Conventional criteria versus new alternatives. Structural Equation Modeling: A Multidisciplinary Journal, 6(1), 1-55.

Ji, L. J. (2010). Is Confucian culture unforgiving? Commentary on Stankov (2010). Learning and Individual Differences, 20(6), $569-570$.

Jones, C., Reichard, C., \& Mokhtari, K. (2003). Are students' learning styles discipline specific? Community College Journal of Research and Practice, 27(5), 363-375.

Koballa Jr., T., Graber, W., Coleman, D. C., \& Kemp, A. C. (2000). Prospective gymnasium teachers' conceptions of chemistry learning and teaching. International Journal of Science Education, 22(2), 209-224.

Lee, M. H., Johanson, R. E., \& Tsai, C. C. (2008). Exploring Taiwanese high school students' conceptions of and approaches to learning science through a structural equation modeling analysis. Science Education, 92(2), 191-220.

Lewis, R. (1997). Learning styles in transition: a study of Indonesian students. Paper presented at the Annual Meeting of the Japan Association of Language Teachers (pp. 1-24).

Li, X., \& Cutting, J. (2011). Rote learning in Chinese culture: reflecting active Confucian-based memory strategies. In L. Jin \& M. Cortazzi (Eds.), Researching Chinese learners (pp. 21-42). London: Palgrave Macmillan. https://doi.org/10.1057/ 9780230299481_2.

Liu, D. (1998). Ethnocentrism in TESOL: Teacher education and the neglected needs of international TESOL students. ELT Journal, 52(1), 3-10.

Manikutty, S., Anuradha, N. S., \& Hansen, K. (2007). Does culture influence learning styles in higher education? International Journal of Learning and Change, 2(1), 70-87.

Marambe, K. N., Vermunt, J. D., \& Boshuizen, H. P. (2012). A cross-cultural comparison of student learning patterns in higher education. Higher Education, 64(3), 299-316.

Marton, F., Dall'Alba, G., \& Beaty, E. (1993). Conceptions of learning. International Journal of Educational Research, 19(3), 277-299.

Marton, F., Watkins, D., \& Tang, C. (1997). Discontinuities and continuities in the experience of learning: an interview study of high-school students in Hong Kong. Learning and Instruction, 7(1), 21-48.

Mullis, I. V. S., Martin, M. O., Foy, P., \& Hooper, M. (2016). TIMSS 2015 international results in science. Chesnut Hill, MA: TIMSS \& PIRLS International Study Center, Lynch School of Education, Boston College.

Neuman, Y., \& Bekerman, Z. (2001). Cultural resources and the gap between educational theory and practice. Teachers College Record, 103(3), 471-484. 
OECD. (2016). PISA 2015 results (volume l): excellence and equity in education, PISA. Paris: OECD Publishing.

OECD. (2017). Education at a glance 2017: OECD indicators. Paris: OECD Publishing. https://doi.org/10.1787/888933560149.

Oxford, R. L., \& Anderson, N. J. (1995). A crosscultural view of learning styles. Language Teaching, 28(4), 201-215.

Park, C. C. (1997). Learning style preferences of Asian American (Chinese, Filipino, Korean, and Vietnamese) students in secondary schools. Equity and Excellence in Education, 30(2), 68-77.

Pask, G. (1976). Styles and strategies of learning. British Journal of Educational Psychology, 46(2), 128-148.

Philbin, M., Meier, E., Huffman, S., \& Boverie, P. (1995). A survey of gender and learning styles. Sex Roles, 32(7), 485-494.

Rachmatullah, A., Diana, S., \& Ha, M. (2017). The effects of curriculum, gender and students' favorite science subject on Indonesian high-school students' conceptions of learning science. Journal of Baltic Science Education, 16(5), 797-812.

Rachmatullah, A., Diana, S., \& Ha, M. (2018a). Identifying Indonesian upper-secondary school students' orientations to learn science and gender effect through the use of structural equation modeling. Journal of Baltic Science Education, 17(4), 633-648.

Rachmatullah, A., \& Ha, M. (2019). Examining high-school students' overconfidence bias in biology exam: a focus on the effects of country and gender. International Journal of Science Education, 41(5), 652-673.

Rachmatullah, A., Lee, J. K., \& Ha, M. (2019). Preservice science teachers' ecological value orientation: a comparative study between Indonesia and Korea. The Journal of Environmental Education, 1-15. https://doi.org/10.1080/00958964.2019. 1633989.

Rachmatullah, A., Roshayanti, F., Shin, S., Lee, J. K., \& Ha, M. (2018b). The secondary-student science learning motivation in Korea and Indonesia. EURASIA Journal of Mathematics, Science and Technology Education, 14(7), 3123-3141.

Richardson, J. T. (2011). Approaches to studying, conceptions of learning and learning styles in higher education. Learning and Individual Differences, 21(3), 288-293.

Robnett, R. D., Chemers, M. M., \& Zurbriggen, E. L. (2015). Longitudinal associations among undergraduates' research experience, self-efficacy, and identity. Journal of Research in Science Teaching, 52(6), 847-867.

Säljö, R. (1979). Learning about learning. Higher Education, 8(4), 443-451.

Schumacker, R. E., \& Lomax, R. G. (2004). A beginner's guide to structural equation modeling. Mahwah: Lawrence Erlbaum Associates, Inc.

Shen, K. M., Lee, M. H., Tsai, C. C., \& Chang, C. Y. (2016). Undergraduate students' earth science learning: relationships among conceptions, approaches, and learning self-efficacy in Taiwan. International Journal of Science Education, 38(9), 1527-1547.

Shin, S., Rachmatullah, A., Roshayanti, F., Ha, M., \& Lee, J. K. (2018). Career motivation of secondary students in STEM: a crosscultural study between Korea and Indonesia. International Journal for Educational and Vocational Guidance, 18(2), 203231. https://doi.org/10.1007/s10775-017-9355-0.

Stankov, L. (2010). Unforgiving Confucian culture: A breeding ground for high academic achievement, test anxiety and selfdoubt? Learning and Individual Differences, 20(6), 555-563.

Suen, H. K., \& Yu, L. (2006). Chronic consequences of high-stakes testing? Lessons from the Chinese civil service exam. Comparative Education Review, 50(1), 46-65.

Swadener, M., \& Soedjadi, R. (1988). Values, mathematics education, and the task of developing pupils' personalities: an Indonesian perspective. In A. J. Bishop (Ed.), Mathematics education and culture (pp. 193-208). Dordrecht: Springer. https://doi.org/10.1007/978-94-017-2209-4_5.

Tavakol, M., \& Dennick, R. (2010). Are Asian international medical students just rote learners? Advances in Health Sciences Education, 15(3), 369-377.

Tsai, C. C. (2004). Conceptions of learning science among high school students in Taiwan: a phenomenographic analysis. International Journal of Science Education, 26(14), 1733-1750.

Tsai, C. C., Ho, H. N. J., Liang, J. C., \& Lin, H. M. (2011). Scientific epistemic beliefs, conceptions of learning science and selfefficacy of learning science among high school students. Learning and Instruction, 21(6), 757-769.

Velayutham, S., Aldridge, J. M., \& Fraser, B. (2012). Gender differences in student motivation and self-regulation in science learning: a multi-group structural equation modeling analysis. International Journal of Science and Mathematics Education, 10(6), 1347-1368.

Watkins, A. J., \& Ehst, M. (2008). Science, technology, and innovation: capacity building for sustainable growth and poverty reduction. Washington D.C: World Bank Publications.

Watkins, D. A., \& Biggs, J. B. (1996). The Chinese learner: Cultural, psychological, and contextual influences. Hong Kong: Comparative Education Research Centre, Faculty of Education, University of Hong Kong; Melbourne: The Australian Council for Educational Research, Ltd.

Wong, J. K. K. (2004). Are the learning styles of Asian international students culturally or contextually based? International Education Journal, 4(4), 154-166.

World Bank. (2017). Indonesia - research and innovation in science and technology project: restructuring (English). Washington, D. C.: World Bank Group.

Yu, C. Y. (2002). Evaluation of model fit indices for latent variable models with categorical and continuous outcomes. In Paper presented at The Annual Conference of the American Educational Research Association, April 4, 2002, New Orleans.

Zeldin, A. L., Britner, S. L., \& Pajares, F. (2008). A comparative study of the self-efficacy beliefs of successful men and women in mathematics, science, and technology careers. Journal of Research in Science Teaching, 45(9), 1036-1058.

Zheng, L., Dong, Y., Huang, R., Chang, C. Y., \& Bhagat, K. K. (2018). Investigating the interrelationships among COLS, ALS, and self-efficacy in learning science. International Journal of Science Education, 40(2), 139-158.

\section{Publisher's Note}

Springer Nature remains neutral with regard to jurisdictional claims in published maps and institutional affiliations. 